\title{
Diagnosis, Staging and Follow-up in Breast Cancer Patients*
}

\author{
Elmar Stickeler \\ Universitätsfrauenklinik Freiburg, Germany
}

Key Words

Breast cancer · MRI - Mammography - Breast ultrasound · Staging · Circulating tumor cells · Follow-up

\section{Summary}

The role of imaging in the diagnosis and local staging of breast cancer is an important issue. Current guidelines recommend mammography for diagnosis of breast cancer, and ultrasound is often used as an additional imaging option. The usage of magnetic resonance imaging (MRI) is a controversial issue. The rationale for initial staging in breast cancer patients is the identification of gross evidence of metastatic disease that would influence further treatment strategies. However, so far, early detection of metastatic disease has had no relevant impact on patient survival. Follow-up examinations can help to detect early recurrences which are potentially curable but might impair quality of life. Disseminated tumor cells (DTCs) are an independent prognostic marker in breast cancer and a potential new staging tool. Detection of DTCs in bone marrow offers a wide spectrum of applications reaching from individual risk assessment to characterization of target antigen expression with consequent appropriate treatment choice. This review describes and discusses new aspects of these topics presented at the $10^{\text {th }}$ St. Gallen International Conference on 'Primary therapy of early breast cancer' 2007.

"Presentations at the 10th International Conference on 'Primary Therapy of Early Breast Cancer', St. Gallen, Switzerland, 2007

\section{Schlüsselwörter}

Mammakarzinom · MRT · Mammographie · Brustultraschall · Staging-Untersuchungen .

Zirkulierende Tumorzellen · Nachsorgeuntersuchungen

\section{Zusammenfassung}

Die bildgebende Diagnostik ist in der modernen Therapieplanung des Mammakarzinoms von zentraler Bedeutung. Aktuelle Leitlinien empfehlen die Mammographie als Methode der Wahl, der Brustultraschall wird häufig als ergänzende Untersuchung zusätzlich eingesetzt. Der Stellenwert der Magnet-Resonanz-Tomographie (MRT)Untersuchungen wird weiterhin sehr kontrovers diskutiert. Die Rationale für die Staging-Untersuchungen beim Mammakarzinom liegt im Nachweis einer klinisch okkulten Metastasierung, die dann zu einem veränderten Therapiekonzept führen würde. Dennoch hat der frühe Nachweis einer Metastierung bisher keinen relevanten Einfluss auf das Überleben dieser Patientinnen gehabt. Die regelmäßigen Nachsorgeuntersuchungen können frühe lokale Rezidive, die potentiell heilbar sind, identifizieren, beeinflussen allerdings möglicherweise negativ die Lebensqualität der Patientinnen. Disseminierte Tumorzellen stellen einen unabhängigen Prognosemarker und ein potentielles Staginginstrument für Patientinnen mit Mammakarzinom dar. Der Nachweis von Tumorzellen im Knochenmark eröffnet ein breites Spektrum von Anwendungsmöglichkeiten, von der individuellen Risikoeinschätzung bis zur Charakterisierung von Zielantigenen auf den Tumorzellen, die eine geeignete zielgerichtete Therapie ("targeted therapy») erlaubt. In dem folgenden Review-Artikel sollen neue Aspekte dieser Themengebiete vorgestellt werden, die auf der 10. St. Gallen Internationalen Konferenz 2007 präsentiert wurden.

\begin{tabular}{|c|c|}
\hline KARGER & (C) 2007 S. Karger GmbH, Freiburg \\
\hline $\begin{array}{l}\text { Fax +4976145207 14 } \\
\text { E-mail Information@Karger.de } \\
\text { www.karger.com }\end{array}$ & $\begin{array}{l}\text { Accessible online at: } \\
\text { www.karger.com/brc }\end{array}$ \\
\hline
\end{tabular}

Prof. Dr. med. Elmar Stickeler

Universitätsfrauenklinik Freiburg Hugstetterstr. 55

79106 Freiburg i. Br., Germany

Tel. +49 761 270-3148, Fax -3148

E-mail elmar.stickeler@uniklinik-freiburg.de 
Local Staging of Breast Cancer with Mammography, Ultrasound, and MRI

The role of imaging in the diagnosis and local staging of breast cancer is still a pertinent and controversial issue. Current guidelines recommend mammography for diagnosing breast cancer, and ultrasound is often used as an additional imaging option. It has to be considered that the sensitivity of mammography is impaired by certain clinical circumstances, such as increased breast density or hyperplasia. Recently, a large trial investigated the role of digital versus conventional film mammography in the screening setting (DMIST trial) with regard to sensitivity for the detection of breast cancer in women with radiographically dense breasts [1]. Over 49,000 asymptomatic women presenting for screening mammography underwent both digital and film mammography. Breast cancer status was ascertained on the basis of a breast biopsy done within 15 months after study entry or a follow-up mammogram obtained at least 10 months after study entry. After a 2-year follow-up, the diagnostic accuracy of digital and film mammography for the whole screening population was similar $(\mathrm{p}=0.18)$. Of clinical importance is that for women under the age of 50 $(\mathrm{p}=0.002)$, women with heterogeneously dense or extremely dense breasts on mammography $(\mathrm{p}=0.003)$, and premenopausal or perimenopausal women $(\mathrm{p}=0.002)$, the accuracy of digital mammography was significantly higher. C. Kuhl, University of Bonn, emphasized in her presentation that digital mammography offers additional advantages over conventional imaging, such as computer-assisted diagnosis (CAD), dose reduction, and facilitated double reading. Furthermore, digital processing might in the future enhance mammographic diagnosis through new technological developments, such as tomosynthesis and contrast-enhanced digital mammography. However, the ACRIN trial revealed that mammography, be it digital or conventional, offers a sensitivity of less than $50 \%$ in the regular mass screening set. This figure is even further reduced to $35 \%$ in women under the age of 50 , in premenopausal women, and in women with a breast density of $>$ ACR2 [1].

Therefore, the diagnostic accuracy of ultrasound in dense breasts might be of clinical importance. Several studies investigated this issue in a screening setting with a total of over 38,000 women [2-4]. An analysis of all studies demonstrated a detection rate of 0.34 and a positive predictive value (PPV) of $14 \%$. The Sydney Breast Imaging Accuracy Study investigated the age-specific sensitivity and specificity of breast ultrasound versus mammography in symptomatic women, e.g. in 480 women ranging in age from 25 to 55 years [5]. In an agematched control design of 240 diagnosed breast cancer patients and 240 women shown not to have cancer, this study revealed a positive imaging by both mammography and ultrasound in $62 \%$ of women. Mammography gave the only positive imaging result for breast cancer in $14 \%$ of all cancer cases and ultrasound in $20 \%$. In conclusion, breast ultrasound is not a screening tool, but can help to detect mammographically occult additional cancers, with an average detection rate of 0.34 and a PPV of $14 \%$ which is comparable to PPV achieved with mammographic screening. These figures are superior to film screen mammography for assessing premenopausal women with symptoms.

These data raise the question of the significance of magnetic resonance imaging (MRI) versus mammography and ultrasound for staging in breast cancer. Especially the aspects of exact tumor mapping, tumor focality/centricity and disease extent are of high importance in order to reach the internationally requested high rates of breast-conserving surgery. Several studies investigated the accuracy of MRI for breast cancer diagnosis [6-9]. In summary, MRI identified additional breast cancers in $14-20 \%$ and offered the most accurate mapping of disease extent, which both had an important impact on the subsequent treatment management.

Despite these intriguing data, there is an ongoing controversy regarding the use of MRI in staging of breast cancer. First, it is argued that recurrence rates are so low that additional cancers diagnosed by MRI may be sufficiently treated by radiotherapy or might be biologically irrelevant. However, a review of the literature shows an ipsilateral recurrence rate of $19 \%$ in patients treated with radiotherapy after breast conservation, and it should be stressed that residual cancer is the main reason for this effect, which is demonstrated by higher recurrence rates in lobular cancers, tumors with close or positive margins and extensive intraductal components [10]. The biological relevance of the additional detected breast cancers was demonstrated by comparative MRI studies which found additional G3 tumors in 35\% [11], featuring the same size and histology distribution compared with the index cancers diagnosed mammographically (unpublished, Braun et al.).

Second, so far, not all data are generated from randomized controlled trials to document the impact on mortality and morbidity or to define subgroups who will profit from the usage of the method. It has to be pointed out that the use of diagnostic mammography was never tested in randomized trial designs either. Furthermore, data from a preoperative MRI study in 160 patients with histologically confirmed breast cancers and an update of the ACRIN trial, which will be published shortly in the New England Journal of Medicine (NEJM), revealed that the probability of detecting additional ipsilateral or contralateral breast cancers by MRI was independent of the histology of the index tumor (lobular vs. ductal), age, menopausal status or mammographic breast density [12]. Additional arguments of the opponents of MRI staging in breast cancer focus on economical issues with frequent false-positive findings and consecutive higher rates of biopsies resulting in high costs for the public health systems. Reviewing the available data, it should be emphasized that the overall specificity and false-positive rate appear to be equivalent in mammography and breast MRI with a mean specificity of 96.0 and $90.8 \%$, respectively, with a superior sensitivity rate of 
$81.3 \%$ vs. $35.5 \%$ for breast MRI [13-16]. Maybe the strongest argument against the usage for MRI in breast cancer staging is the fear of higher mastectomy rates, thereby annihilating the advantages of breast-conserving surgery achieved over the last decades. Obviously, this is true if old paradigms are applied to this new situation and established recommendations for mammographically detected multicentric disease are adopted. C. Kuhl suggested in her presentation that mastectomy might not be appropriate for every MRI-detected multicentric cancer. Further studies are warranted to elucidate the optimal treatment strategies for this situation.

In summary, MRI for staging of breast cancer in 2007 is superior to mammography and ultrasound, irrespective of patient age, menopausal status, breast density and histology of the index cancer. The method provides the breast surgeon with an accurate roadmap for surgery, although the adequate treatment strategy for MRI-detected multicentric breast cancers is not yet known and has to be evaluated under controlled conditions.

\section{Role of Baseline Staging and Follow-up}

The rationale for initial staging is the identification of gross evidence of metastatic disease that would alter the further treatment strategy. However, E. Winer, Dana Faber Cancer Institute, pointed out that the relevance of knowing that a patient has minimal evidence of metastatic disease is not known. First, imaging findings will require a histological confirmation, generally achieved by biopsies which may cause harm, and it is still unclear if a change in treatment strategies upon these findings will impact on patients' overall survival or quality of life. Second, diagnostic tests produce false-positive results, leading to additional non-invasive testing, subsequent biopsies, delays in adjuvant treatment and psychological stress for the patient.

Available staging procedures in asymptomatic breast cancer patients include chest imaging (X-ray, computed tomography (CT)), hepatic/abdominal imaging (ultrasound, CT) and bone imaging (bone scan) as well as total body scans (positron emission tomography (PET), PET CT). Reviewing the existing data, chest radiography in primary breast cancer patients detected lung metastasis in $0.1 \%$ of stage I, $0.2 \%$ of stage II and $1.7 \%$ of stage III disease [17]. In concordance, liver ultrasound found occult metastasis in $0 \%$ of stage I, $0.4 \%$ of stage II and $2.0 \%$ of stage III disease, representing a total of $0.6 \%$ of all examined patients [17]. The role of CT scans in breast cancer staging, although replacing the conventional ultrasound and chest radiography in the US, is not scientifically evaluated, and pathological findings should be interpreted with caution. This is also true for pelvic CT which cannot be recommended as a standard baseline staging tool. One large study on 2,400 patients found $0.5 \%$ pelvic metastasis (13 patients) as sole manifestation leading to 204 additional radio- logical procedures and 50 subsequent surgical procedures [18]. Analysis of bone scans demonstrated an overall finding of $3.1 \%$ of bone metastases in 5,400 patients, with $0.5 \%$ in stage I, $2.4 \%$ in stage II, and $8.3 \%$ in stage III disease [17]. The upcoming modern PET scans are, like the CT scans, not sufficiently evaluated as a staging procedure in breast cancer. Carr et al. [19] presented an abstract at the ASCO meeting 2006 on 189 women who had PET scans performed prospectively at the time of breast cancer diagnosis. PET detected abnormalities in 42 women. 59 lesions in 33 women were considered suspicious. Only 6 truly positive women were identified, of whom 4 women had lesions seen already in standard imaging. Furthermore, 22 patients needed additional tests such as CT and MRI. Taking all these data into consideration, E. Winer recommended baseline staging for early breast cancer patients for stage III disease with larger tumors and any nodal involvement and 4 or more axillary lymph node metastases. Bone scans should already be performed in high risk stage II disease. Furthermore, staging studies are advised in the presence of any symptoms or laboratory abnormalities. The increasing knowledge about tumor biology, breast cancer subtypes and prognostic profiles will influence the decision to perform staging procedures on an individual level.

Follow-up and surveillance measures after the diagnosis of breast cancer are questioned with regard to a benefit for prolonging survival or improving quality of life. However, with increasing cure rates and earlier detection, there is a growing need for short- and long-term follow-up of women with breast cancer including ductal carcinoma in situ (DCIS). The goals are to detect new breast primaries and locoregional recurrences in a curable stage, to address complications of past therapies and to provide psychological support and medical advice, to monitor ongoing therapy (e.g. extended endocrine therapies) and to diagnose advanced disease. The incidence of new primaries is approximately $0.5 \%$ per year, with an increased risk in gene mutation carriers and young people as well as patients with higher breast density [20]. Besides breast self-examination, clinical breast examination and mammography, MRI is an available option to detect new primaries. Mammography, however, has weak evidence when screening for secondary cancers. Individualized approaches instead of the routinely performed yearly mammography, e.g. new diagnostic studies (MRI) or preventive strategies in higher risk patients, should be considered.

Follow-up is also important for patients after mastectomy. Especially young women with higher stages, vascular involvement and endocrine non-responsive disease are at high risk. Buchanan et al. [21] reported on the local recurrence rates in over 1,000 women after mastectomy. Predominantly, local recurrence was the first site of disease, and the majority of patients were and stayed free of distant recurrence. Furthermore, a recent meta-analysis underlined the importance of follow-up visits demonstrating that $47 \%$ of local recurrences after mastectomy were detected at routine visits when patients 
were asymptomatic [22]. So far, it is not known if an early diagnosis of locoregional recurrence will extend survival due to lead time and length time bias. But, a better local control given by earlier diagnosis is definitively beneficial with regard to quality of life. Therefore, risk-adapted follow-up strategies should be considered.

The detection of distant metastasis is a major concern for patients. So far, the early detection of metastatic disease has not been shown to improve patient outcome [23]. However, so far, none of the randomized trials in this field included more sensitive imaging techniques and modern treatment modalities, such as trastuzumab, aromatase inhibitors or taxanes. With regard to quality of life, it has to be considered that surveillance might have a potential negative impact on the patients due to the discomfort of the screening procedures, increased anxiety in the period around the screening and additional procedures generated by false-positive results [24].

In summary, surveillance after diagnosis of breast cancer is an important measure to screen for secondary primaries and early local recurrences which are potentially curable. The significance of early detection of distant metastatic disease in breast cancer patients is unclear and a potential issue for further evaluation, particularly if new treatments are developed. Furthermore, physicians performing follow-up should be aware of the physical and psychological consequences of breast cancer and treatment side effects. Surveillance guidelines from the ASCO and the Organ Committee 'Mamma' of the working group Gynecological Oncology (AGO) are helpful tools for follow-up care physicians, but the frequency of visits might be individualized based on disease risk, complications of therapy, and needs of the patient. In general, visits every 6 months for 2-5 years followed by annual visits appear to be reasonable.

\section{Disseminated Tumor Cells}

The pooled analysis of Braun et al. [25] including 4,703 patients with a 10-year follow-up provided conclusive level-I evidence that the presence of disseminated tumor cells (DTCs) in bone marrow is a significant indicator of poor prognosis in breast cancer patients. These results were confirmed by Janni et al. [26] who performed bone marrow aspirations in 726 patients with primary breast cancer at the time of diagnosis and
32 months thereafter. All patients were recurrence-free, clinical follow-up was 55 months, and $16 \%$ of patients were DTCpositive. The presence of DTC in the follow-up aspiration was a associated with a response rate (RR) of 6.6 for overall survival in comparison to an RR of 2.9 for lymph node metastasis at the time of diagnosis. S. Braun, University of Innsbruck, addressed the question if DTCs are already a useful clinical tool in breast cancer management, especially for risk assessment, treatment planning of targeted therapies or monitoring treatment efficacy in future clinical trials. First, he demonstrated that DTCs present a malignancy-type genotype and are genetically as well as phenotypically different from the primary tumor. Only a minority of DTCs carries for example Her2 amplifications, and these amplifications are inconsistent compared to the primary tumor. This phenomenon represents important evidence that Her2 amplification either develops in DTCs after tumor cell spread or it is only present in a small clone within phenotypically different tumor cells. These observations, especially the discrepancy of Her2 expression in primary tumors vs. DTCs, stress the pertinent issue of failing to choose the correct targeted treatment options and underline the importance of optimized patient selection for targeted therapies. In this regard, tumor cell biology as determined by DTC analyses might help in the future to overcome this drawback.

Another important application of DTC detection is the monitoring of therapeutic efficacy in the adjuvant setting. There is growing evidence for the ability of targeted antibody-based therapy, in contrast to polychemotherapy, to eliminate DTCs in the bone marrow. The next consecutive step will be the development of clinical trials for patients with a DTC persistence in the bone marrow after adjuvant therapy. These trials might investigate the benefit of secondary adjuvant treatment strategies. A first example for a trial design based on DTC detection is the Austrian-German-Norwegian Cooperative trial ‘@fame' which will analyze the effect of endocrine therapy in postmenopausal women with tumor cells in the bone marrow.

In summary, the detection of DTCs in bone marrow offers the possibility to assess the individual risk of relapse and to determine treatment efficacy immediately or even during treatment, and allows the characterization of target antigen expression on the actual target cell with subsequent appropriate treatment choice.

\section{References}

$\checkmark 1$ Pisano ED, Gatsonis C, Hendrick E, Yaffe M, Baum JK, Acharyya S, Conant EF, Fajardo LL, Bassett L, D’Orsi C, Jong R, Rebner M: Diagnostic performance of digital versus film mammography for breast-cancer screening. N Engl J Med 2005; 353:1773-83.

2 Gordon PB, Goldenberg SL: Malignant breast masses detected only by ultrasound. A retrospective review. Cancer 1995;76:626-30.
3 Buchberger W, Niehoff A, Obrist P, DeKoekkoekDoll P, Dunser M: Clinically and mammographically occult breast lesions: detection and classification with high-resolution sonography. Semin Ultrasound CT MR 2000;21:325-36.

4 Kolb TM: Ultrasound boosts cancer detection in dense breasts. Diagn Imaging (San Franc) 2000;22: 103-4, 107-11.
5 Houssami N, Irwig L, Simpson JM, McKessar M, Blome S, Noakes J: Sydney Breast Imaging Accuracy Study: Comparative sensitivity and specificity of mammography and sonography in young women with symptoms. AJR Am J Roentgenol 2003;180: 935-40. 
6 Bedrosian I, Mick R, Orel SG, Schnall M, Reynolds C, Spitz FR, Callans LS, Buzby GP, Rosato EF, Fraker DL, Czerniecki BJ: Changes in the surgical management of patients with breast carcinoma based on preoperative magnetic resonance imaging. Cancer 2003;98:468-73.

7 Schnall MD, Blume J, Bluemke DA, Deangelis GA, Debruhl N, Harms S, Heywang-Kobrunner SH, Hylton N, Kuhl CK, Pisano ED, Causer P, Schnitt SJ, Smazal SF, Stelling CB, Lehman C, Weatherall PT, Gatsonis CA: MRI detection of distinct incidental cancer in women with primary breast cancer studied in IBMC 6883. J Surg Oncol 2005;92:32-8.

-8 Fischer U, Kopka L, Grabbe E: Breast carcinoma: effect of preoperative contrast-enhanced MR imaging on the therapeutic approach. Radiology 1999; 213:881-8.

9 Van Goethem M, Schelfout K, Dijckmans L, van der Auwera JC, Weyler J, Verslegers I, Biltjes I, de Schepper A: MR mammography in the pre-operative staging of breast cancer in patients with dense breast tissue: comparison with mammography and ultrasound. Eur Radiol 2004;14:809-16.

10 Van Dongen JA, Voogd AC, Fentiman IS, Legrand C, Sylvester RJ, Tong D, van der Schueren E, Helle PA, van Zijl K, Bartelink H: Long-term results of a randomized trial comparing breast-conserving therapy with mastectomy: European Organization for Research and Treatment of Cancer 10801 trial. J Natl Cancer Inst 2000;92:1143-50.

-11 Bluemke DA, Gatsonis CA, Chen MH, DeAngelis GA, DeBruhl N, Harms S, Heywang-Kobrunner SH, Hylton N, Kuhl CK, Lehman C, Pisano ED, Causer P, Schnitt SJ, Smazal SF, Stelling CB, Weatherall PT, Schnall MD: Magnetic resonance imaging of the breast prior to biopsy. Jama 2004; 292:2735-42.

12 Lehman CD, Gatsonis C, Kuhl CK, Hendrick RE, Pisano ED, Hanna L, Peacock S, Smazal SF, Maki DD, Julian TB, DePeri ER, Bluemke DA, Schnall MD: MRI evaluation of the contralateral breast in women with recently diagnosed breast cancer. $\mathrm{N}$ Engl J Med 2007;356:1295-303.
13 Kriege M, Brekelmans CT, Boetes C, Besnard PE, Zonderland HM, Obdeijn IM, Manoliu RA, Kok T, Peterse H, Tilanus-Linthorst MM, Muller SH, Meijer S, Oosterwijk JC, Beex LV, Tollenaar RA, de Koning HJ, Rutgers EJ, Klijn JG: Efficacy of MRI and mammography for breast-cancer screening in women with a familial or genetic predisposition. $\mathrm{N}$ Engl J Med 2004;351:427-37.

14 Warner E, Plewes DB, Hill KA, Causer PA, Zubovits JT, Jong RA, Cutrara MR, DeBoer G, Yaffe MJ, Messner SJ, Meschino WS, Piron CA, Narod SA: Surveillance of BRCA1 and BRCA2 mutation carriers with magnetic resonance imaging, ultrasound, mammography, and clinical breast examination. Jama 2004;292:1317-25.

15 Leach MO, Boggis CR, Dixon AK, Easton DF, Eeles RA, Evans DG, Gilbert FJ, Griebsch I, Hoff RJ, Kessar P, Lakhani SR, Moss SM, Nerurkar A, Padhani AR, Pointon LJ, Thompson D, Warren RM: Screening with magnetic resonance imaging and mammography of a UK population at high familial risk of breast cancer: a prospective multicentre cohort study (MARIBS). Lancet 2005;365: 1769-78.

16 Kuhl CK, Schrading S, Leutner CC, MorakkabatiSpitz N, Wardelmann E, Fimmers R, Kuhn W, Schild HH: Mammography, breast ultrasound, and magnetic resonance imaging for surveillance of women at high familial risk for breast cancer. J Clin Oncol 2005;23:8469-76.

17 Myers RE, Johnston M, Pritchard K, Levine M, Oliver T: Baseline staging tests in primary breast cancer: a practice guideline. CMAJ 2001;164: 1439-44.

18 Drotman MB, Machnicki SC, Schwartz LH, Winston CB, Yoo HH, Panicek DM: Breast cancer: assessing the use of routine pelvic $\mathrm{CT}$ in patient evaluation. AJR Am J Roentgenol 2001;176:1433-6.

19 Carr CE, Conant EF, Rosen MA, Schnall MD, Davidson R: The impact of FDG PET in the staging of breast cancer. J Clin Oncol 2006;24:18S(abstr 530).
20 Metcalfe K, Lynch HT, Ghadirian P, Tung N, Olivotto I, Warner E, Olopade OI, Eisen A, Weber B, McLennan J, Sun P, Foulkes WD, Narod SA: Contralateral breast cancer in BRCA1 and BRCA2 mutation carriers. J Clin Oncol 2004;22:2328-35.

21 De Bock GH, Bonnema J, van der Hage J, Kievit J, van de Velde CJ: Effectiveness of routine visits and routine tests in detecting isolated locoregional recurrences after treatment for early-stage invasive breast cancer: a meta-analysis and systematic review. J Clin Oncol 2004;22:4010-8.

22 Buchanan CL, Dorn PL, Fey J, Giron G, Naik A, Mendez J, Murphy C, Sclafani LM: Locoregional recurrence after mastectomy: incidence and outcomes. J Am Coll Surg 2006;203:469-74.

23 Liberati A: The GIVIO trial on the impact of follow-up care on survival and quality of life in breast cancer patients. Interdisciplinary Group for Cancer Care Evaluation. Ann Oncol 1995;6(suppl 2):41-6.

24 Barton MB, Morley DS, Moore S, Allen JD, Kleinman KP, Emmons KM, Fletcher SW: Decreasing women's anxieties after abnormal mammograms: a controlled trial. J Natl Cancer Inst 2004;96:529-38.

25 Braun S, Vogl FD, Naume B, Janni W, Osborne MP, Coombes RC, Schlimok G, Diel IJ, Gerber B, Gebauer G, Pierga JY, Marth C, Oruzio D Wiedswang G, Solomayer EF, Kundt G, Strobl B, Fehm T, Wong GY, Bliss J, Vincent-Salomon A, Pantel K: A pooled analysis of bone marrow micrometastasis in breast cancer. N Engl J Med 2005; 353:793-802.

26 Janni W, Wiedswang G, Fehm T, Jueckstock J, Borgen E, Rack B, Braun S, Sommer H, Solomayer E, Pantel K, Nesland JM, Genss E, Friese K, Naume $\mathrm{B}$ : Persistence of disseminated tumor cells (DTC) in bone marrow (BM) during follow-up predicts increased risk for relapse up-date of the pooled European data. Breast Cancer Res Treat 2006;100 (suppl 1):abstr 18. 